\title{
A CRITICAL EVALUATION OF KENYON'S SHAG (PHALACROCORAX [STICTOCARBO] KENYONI)
}

\author{
Sievert RohWer, ${ }^{1,3}$ Christopher E. Filardi, ${ }^{1}$ Kimberly S. BostWick, ${ }^{2}$ AND \\ A. TOWNSEND PETERSON ${ }^{2}$ \\ 'Burke Museum and Department of Zoology, Box 353010, University of Washington, \\ Seattle, Washington 98195, USA; and \\ ${ }^{2}$ Natural History Museum and Biodiversity Research Center, University of Kansas, Lawrence, Kansas 66045, USA
}

\begin{abstract}
We examine the validity of Phalacrocorax [Stictocarbo] kenyoni, which was described by Siegel-Causey (1991) from the Aleutian Islands using midden remains and existing skeletal specimens. We emphasize a morphometric evaluation of the taxon using 224 skeletal specimens of North Pacific cormorants, but we also evaluate the qualitative characters originally used to characterize $P$. kenyoni. Principal components and discriminant function analyses of 14 skeletal characters failed to support the validity of the species. Similarly, all seven of the character states that Seigel-Causey described as unique to $P$. kenyoni also were found in P. pelagicus and $P$. urile. Thus, the three type specimens of $P$. kenyoni appear to be $P$. pelagicus. Although we could not confirm the validity of $P$. kenyoni, our morphometric analyses revealed that $P$. pelagicus individuals from the central Aleutians are smaller than those from surrounding populations. Received 11 December 1998, accepted 20 July 1999.
\end{abstract}

Siegel-Causey (1991) described a new species of cormorant from the Aleutian Islands; he named it Stictocarbo (=Phalacrocorax) kenyoni, reflecting his prior studies of major clades in the Phalacrocoracidae (Siegel-Causey 1988). Siegel-Causey first discovered this bird in midden remains from Amchitka Island in the far western Aleutian Islands but later found three recent skeletal specimens that he ascribed to kenyoni and designated as types (Siegel-Causey 1991, Siegel-Causey et al. 1991). No other specimens of this species exist. The external appearance of $P$. kenyoni remains undescribed, and the species was not accepted as valid by AOU (1998).

To facilitate an evaluation of the validity of $P$. kenyoni, the University of Washington Burke Museum (UWBM) salvaged every intact cormorant recovered from the beaches of Prince William Sound, Alaska, following the Exxon Valdez oil spill of 24 March 1989. All were preserved as skeletal specimens, and when carcasses were not too rotten, associated extended wings and flat skins also were preserved. Our analyses focused primarily on a morphometric evaluation of $P$. kenyoni using 224 skeletal specimens of cormorants from the North Pacific. We also evaluated the qualitative characters that Siegel-Causey (1991) used to characterize $P$.

${ }^{3}$ E-mail: rohwer@u.washington.edu kenyoni, based on detailed examinations of a more limited reference series of specimens. Rohwer and Filardi were responsible for the morphometric analyses, and Bostwick and Peterson performed the qualitative analyses.

\section{MethodS}

Hereafter, we refer to the three North Pacific cormorants as kenyoni, pelagicus, and urile for Kenyon's Shag ( $P$. kenyoni), Pelagic Cormorant ( $P$. pelagicus), and Red-faced Cormorant (P. urile), respectively. Table 1 provides general localities and dates of collection for the specimens used in our morphometric analyses. The three kenyoni specimens were from Amchitka Island, Alaska; the 25 urile specimens were from Prince William Sound, or from other Alaskan localities to the west and north; localities for the 196 pelagicus specimens are plotted in Figure 1. About one-third of the 196 pelagicus specimens were collected from May to August and thus are likely to be from breeding areas. Although many of the specimens were not yet of breeding age, young pelagicus are known to summer near the colonies where they hatched (Palmer 1962).

Qualitative characters.-Because Seigel-Causey's diagnosis of kenyoni was based on seven autapomorphic skeletal characters (Siegel-Causey 1991: appendix 2) and its small size, we paid special attention to the qualitative characters of skeletal morphology described in his Appendix 1. Our interpretations of Siegel-Causey's characters were based on standard avian anatomical references (Howard 1929, George and Berger 1966, Baumel et al. 1979, Baumel and Witmer 
TABLE 1. Specimens examined by species, locality, and season (breeding $=1$ May to 31 August). Map symbols for pelagicus refer to Figure 1 .

\begin{tabular}{lccc}
\hline \hline \multicolumn{1}{c}{ Locality } & Map symbol & $\begin{array}{c}\text { Breeding } \\
\text { season }\end{array}$ & $\begin{array}{c}\text { Nonbreeding } \\
\text { season }\end{array}$ \\
\hline Aleutian Islands & $\boldsymbol{P .}$ kenyoni & & 3 \\
& $-\quad \boldsymbol{P}$ urile & 0 & 10 \\
Alaska & - & 15 & \\
& P. pelagicus & & 124 \\
Valdez and Southeast Alaska & $\mathrm{V}$ & 29 & 1 \\
Aleutian Islands & $\mathrm{A}$ & 17 & 3 \\
Pribilofs and northern Alaska & $\mathrm{P}$ & 0 & 3 \\
British Columbia and Washington & $\mathrm{W}$ & 3 & 6 \\
California & $\mathrm{C}$ & 2 & 0 \\
Russia & $\mathrm{R}$ & 7 & 0 \\
Japan & $\mathrm{J}$ & 1 & 150 \\
Totals & - & 74 & \\
\hline
\end{tabular}

1993) and on careful inspection of specimens, including one of the paratypes (UWBM 18613). For the purpose of evaluating the validity of each character in diagnosing kenyoni, we assembled a reference series of six male (UWBM 22442, 44193, 44194, 44403,
48557,48617 ) and six female (UWBM 14484, 38795, $42012,43071,44195,44402)$ pelagicus, and six male (UWBM 48619, 50610, 52084, 52090, 52091, 52094) and six female (UWBM 50611, 50612, 52086, 52089, 52093, 52107) urile, the other two "Stictocarbo" shags

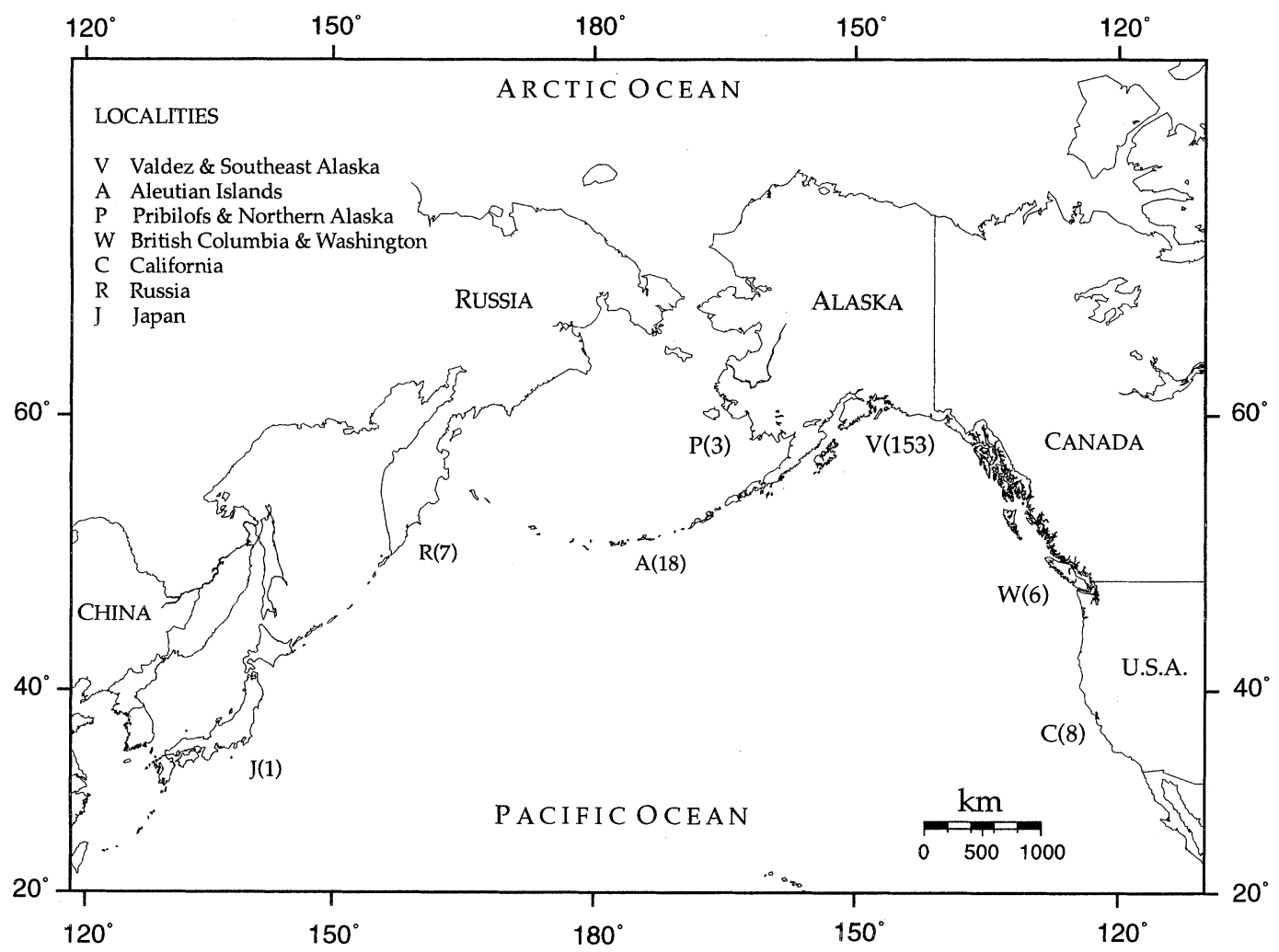

FIG. 1. North Pacific localities for the 196 pelagicus specimens used in the morphometric analyses. Symbols for the locality names are followed by sample sizes in parentheses. 
TABLE 2. Description of the 14 skeletal characters used in the morphometric analyses. Terminology used in the character descriptions follows Baumel and Witmer (1993).

\begin{tabular}{|c|c|}
\hline Character & Description \\
\hline Cranium depth & $\begin{array}{l}\text { Distance from center of external base of cranium to highest point of } \\
\text { calvaria (skull cap) }\end{array}$ \\
\hline Cranium length & $\begin{array}{l}\text { From craniofacial flexion zone (hinge) to dorsal rim of foramen mag- } \\
\text { num }\end{array}$ \\
\hline Maxilla length & $\begin{array}{l}\text { From craniofacial flexion zone (hinge) to rostrum of maxilla (tip of } \\
\text { premaxilla) }\end{array}$ \\
\hline Coracoid length & From acrocoracoid to lateral process of sternal end of coracoid \\
\hline Humerus length & From head of humerus to ventral condyle at its distal end \\
\hline Ulna length & From olecranon to ventral condyle at its dorsal end \\
\hline Carpometacarpus length & From carpal trochlea to distal end of major metacarpal \\
\hline Sternum length & $\begin{array}{l}\text { From dorsal spine of sternal rostrum to caudal border of sternal body } \\
\text { at midline }\end{array}$ \\
\hline Sternum width & Transverse distance between the first costal processes of each side \\
\hline Synsacrum length & $\begin{array}{l}\text { From corpus (body) of cranial-most synsacral vertebra to that of the } \\
\text { caudal-most synsacral vertebra }\end{array}$ \\
\hline Pelvis width & $\begin{array}{l}\text { Distance between left and right antitrochanters that form the dorsal } \\
\text { rims of the acetabula }\end{array}$ \\
\hline Femur length & From tip of femoral trochanter to lateral condyle at its distal end \\
\hline Tibiotarsus length & $\begin{array}{l}\text { From patellar articular surface of the cranial cnemial crest to medial } \\
\text { condyle at its distal end }\end{array}$ \\
\hline Tarsometatarsus length & $\begin{array}{l}\text { From the intercondylar eminence at its proximal end to the most distal } \\
\text { metatarsal trochlea }\end{array}$ \\
\hline
\end{tabular}

in the region. All urile reference specimens were from Alaska. It was important that the pelagicus reference series included large birds taken outside the Aleutians because kenyoni is small and has been reported only from the Aleutians. For pelagicus males, these specimens came from Prince William Sound, Alaska $(n=2)$, Russia $(n=3)$, and Washington $(n=$ $1)$; for pelagicus females, these specimens came from Russia $(n=2)$, Washington $(n=3)$, and British Columbia $(n=1)$. The birds from Russia and Prince William Sound were large. Each character was scored on each specimen by Bostwick and Peterson to evaluate the hypothesis that these qualitative characters diagnose the species.

Quantitative characters.-For our morphometric analyses, we used the 14 skeletal measurements defined in Table 2. All were large enough to be taken accurately with dial calipers. Some of these measurements are difficult to replicate unless other workers first learn to match the measurements we made for individual specimens (available from Rohwer or Filardi). The problem lies not in the repeatability of our measurements, but in interpreting our definitions for them (Table 2). Unless the same measurements are taken, errors between observers seriously affect results. With one exception (see below), Filardi made all measurements.

The holotype specimen for kenyoni is housed at the United States National Museum (USNM 431164), and the two paratypes are at the University of Washington Burke Museum (UWBM 18613, 18614). Because the USNM does not lend type specimens, we sent three pelagicus measured by Filardi to the
USNM. After using these specimens to learn to repeat our measurements, Brian Schmidt measured the kenyoni type for us.

Resolving problems with the morphometric data.-Although most of the Valdez birds were in good condition, some were too rotten to be sexed by gonads, and two were initially misidentified to species by their preparators. Additionally, a few specimens from the Valdez collection and from other museums had broken elements that could not be measured. We have dealt with these problems as follows.

Specimens with missing characters were included in the morphometric analyses only if two or fewer characters were missing. Twenty-seven of the 225 specimens we measured had missing characters; 1 with many missing characters was excluded, 23 had a single missing character, and 3 had two missing characters. We estimated values for missing characters in univariate regressions using the character most strongly correlated with the missing character as an estimator. All species and sexes were combined for this regression analysis because sex and species determinations had not yet been evaluated. We later reassessed these estimates using correlations between characters for within-sex and within-species analyses; however, changes in estimates were so small (typically $<1 \mathrm{~mm}$ ) that reestimates were not used. Less than $1 \%$ of our 3,136 morphometric values were estimated, making the quality of our data matrix high.

With the full matrix of morphometric measurements, our next step was to resolve problems in sex determination. Several specimens were not sexed by 
their preparators, and others apparently were sexed erroneously. In preparing the Valdez series and a group of 23 freshly collected pelagicus from Washington, we learned that testes of first-year males are flattened and so little developed that, without carefully checking for paired gonads, testes are easily mistaken for ovaries (S. Rohwer and C. Filardi unpubl. data). For this reason, we felt that correcting the sex on specimens lacking measurements of gonad size was appropriate.

To assign sexes we pooled all sexed specimens ( $n$ $=214$ ) in a discriminant analysis. We pooled species for this analysis because this analysis needed to precede the evaluation of species identity and because our samples of urile and kenyoni were too small to be treated separately. Two of the three specimens designated as kenyoni by Siegel-Causey (1991) are unsexed, and we measured only 25 specimens of urile. We accepted the sexes assigned to specimens by our discriminant analysis except for three University of Kansas Natural History Museum (KUNHM) specimens collected by Siegel-Causey in the Aleutian Islands, each of which had gonad measurements. Finally, we corrected two errors of species identification in which urile specimens had been identified as pelagicus (UWBM 50583 and 52123). Both were Valdez casualties, presumably encased in tar-like crude oil, which made identification by their preparators difficult.

Morphometric analyses.-Terminology surrounding discriminant analysis is confusing because distinctions are often drawn between the two-group case and the case of more than two groups. In two-group comparisons, the new linear combination of the original variables that best separates them is called the discriminant function. When more than two groups are to be discriminated, most references shift names and apply the name canonical analysis. Thus, the first discriminator is called the first canonical axis, or canonical variate 1 , and so on for the $n-1$ variates needed to plot the $n$ centroids for the known groups (see Overall and Klett 1972). Both analyses follow the same principle of maximizing the ratio of the between-group variance to the pooled within-group variance. As in principal components analysis (PCA), the canonical axes obtained from a multiple discriminant analysis are orthogonal to each other, with the first axis explaining the greatest difference between the groups, the second the next greatest, and so on.

In all of our multivariate analyses, we used the corrected data matrix (missing measurements replaced, sexes and species assigned or corrected). We evaluated the validity of kenyoni using discriminant and canonical analyses. Our first approach was a canonical analysis using urile males and females and pelagicus males and females as known groups. The three kenyoni specimens were then projected onto these axes. In our discussions of discriminant analysis, posterior probabilities refer to the probabilities of group affiliation assigned by the analysis after the best discrimination had been achieved using the $a$ priori groupings.

We also used PCA to evaluate variation in the full matrix of 224 specimens (kenyoni, urile, pelagicus) and in certain subsets of this matrix. Principal components analysis is useful because it economically summarizes variation in morphological data without using information about group membership. We extracted principal components from correlation matrices to avoid weighting larger characters more heavily than small characters, as occurs with covariance matrices. All of our analyses were done using JMP 3.1 and StatView 5.0 from SAS Institute.

\section{RESULTS}

\section{Qualitative Analyses}

Here we summarize the results of our inspection of the seven derived characters for kenyoni (Siegel-Causey 1991: appendix 2). We first attempt to establish the synonymy of SiegelCausey's anatomical names with those of Baumel and Witmer (1993), pointing out ambiguities. We then describe the features emphasized in our examination of variation in these qualitative characters; this represents our best attempt to reconstruct what Siegel-Causey (1991) examined. Finally, we report the results of our comparison of the paratype with the reference series. Character descriptions (anatomical names in italics) are followed by a list of possible character states (see Siegel-Causey 1991: appendix 1). See Seigel-Causey (1991: appendix 2) for a description of how the character states apply to the three taxa.

Character 1 [mandible]._- "Fossa aditus: (a) extends usually $1 / 3$ (but no more than $1 / 2$ ) the length of the insertion of $\mathrm{M}$. pseudotemporalis; (b) extends at least $3 / 4$ the length of the insertion" (Siegel-Causey 1991). The fossa aditus canalis mandibulae (Baumel and Witmer 1993) presumably is the same feature as Siegel-Causey's fossa aditus. Its general location is illustrated, but the illustration is insufficient to permit judging its extent with confidence. Baumel et al. (1979) recognized two muscles that create the fossa: $M$. pseudotemporalis superficialis and M. pseudotemporalis profundus; they noted that M. pseudotemporalis profundus is sometimes synonymous with M. pseudotemporalis, but they did not illustrate either. In our reference series, a muscle scar was found near 
the fossa aditus, but the nature of that impression varied greatly among specimens, such that comparing its extent among specimens required some subjectivity.

The fossa aditus and the insertion of the $M$. pseudotemporalis were evaluated as follows. The fossa aditus was considered to be the subtile depression at the proximal end of the mandible on the inside of the ramus. The insertion of $\mathrm{M}$. pseudotemporalis was assumed to be the long, narrow groove running underneath, and often beyond, the fossa aditus. The extent of the insertion varied among individuals, such that the fossa aditus extended relatively farther in the paratype than in most of the reference series. However, we did not find this character state to be unique to the paratype; at least one urile and one pelagicus in the reference series were as extreme as the paratype.

Character 5 [humerus].--Attachment of $M$. dorsalis scapulae: (a) proximal most scar lateral to distal scar; (b) both scars in line on bicipital crest" (Siegel-Causey 1991). M. dorsalis scapulae is synonymous with $\mathrm{M}$. scapulohumeralis posterior (George and Berger 1966) and M. scapulohumeralis caudalis (Baumel and Witmer 1993). George and Berger (1966) describe this muscle in detail. M. scapulohumeralis caudalis is a single muscle that inserts onto the humerus by a single tendon, but Siegel-Causey's (1991) character description refers to the existence of two scars. Furthermore, "lateral" on the bicipital crest is difficult to determine, given the difference of orientation between the bone and the axis of the bird's body, as well as the curved surface of the bicipital crest. We assumed that Siegel-Causey's "scars" were equivalent to the two most obvious protuberances on the bicipital crest, and that he used "lateral" in reference to the bird's body, rather than to the axis of the bone. We found that $33 \%$ of urile and $42 \%$ of pelagicus in the reference series exhibited the state that we understood to be derived in kenyoni, and that the paratype failed to show the derived state.

Character 7 [humerus].- "Ligamental furrow: (a) does not reach head; (b) distinctly notches head (Character 64 of Siegel-Causey, 1988)" (Siegel-Causey 1991). This character is not illustrated and is defined exactly the same way in both references. Baumel et al. (1979) did not recognize a "ligamental furrow," but referred to a sulcus ligamentus transversus, and Baumel and Witmer (1993) recognized a sulcus transversus. Siegel-Causey (1988) followed the nomenclature of Owre (1967) and Howard (1929). Howard illustrates the furrow clearly, but from an orientation different from that required to see the character. We looked at the dorsolateral profile of the head of the humerus for a notch and found it on the paratype, although its distinctness depended on the orientation from which the bone was viewed. We then examined the reference series to see if the same notched profile existed. In all, $25 \%$ of pelagicus and $18 \%$ of urile showed the notch, although not as noticeably as the paratype.

Character 13 [femur].- "Attachment of M. obturator externus + internus: (a) elliptical, shallow, indistinct; (b) deeply excavated, broad, subcircular; (c) deeply excavated, narrow (Character 5 of Siegel-Causey and Lefevre, 1989)" (Siegel-Causey 1991). This illustration of this character was unclear and lacked labels in Siegel-Causey and Lefevre (1989). Baumel and Witmer (1993) did not recognize M. obturator externus or M. obturator internus, placing them in the synonymy of $\mathrm{M}$. obturatorius lateralis and $\mathrm{M}$. obturatorius medialis, respectively. We assumed that the impressiones obturatoriae (Baumel et al. 1979) were the attachments to which Siegel-Causey (1991) referred. However, illustrations and descriptions in Baumel et al. (1979) were insufficient to determine to which feature of the femur Siegel-Causey (1991) referred. Scrutiny of the impressiones obturatoriae in our reference series did not reveal the patterns described. The attachment in urile was smaller than in the other species, which does not agree with Siegel-Causey's (1991) general description ("deeply excavated, broad, subcircular"). No discrete variation was observed in the reference series; the paratype may be narrower in a quantitative (but not qualitative) sense.

Character 14 [femur].--“Attachment of M. flexor perforatus digiti II: (a) indistinct; (b) deeply excavated without noticeable lateral bony margins; (c) deeply excavated with robust lateral bony crest" (Siegel-Causey 1991). This muscle is synonymous with $\mathrm{M}$. flexor perforans et perforatus digiti II (Baumel and Witmer 1993). Neither Baumel and Witmer (1993) nor Howard (1929) described the bony feature attributed to this attachment on the femur. The paratype was indeed deeply excavated with a robust lateral 
crest; however, we also found this state on $50 \%$ of pelagicus and $18 \%$ of urile in our reference series.

Character 16 [femur].- "Attachment of M. flexor hallucis longis: (a) medial margin marked by distinct line just adjacent to medial prominence of external condyle; (b) medial margin coincident with medial prominence, causing the superior aspect to appear sharply produced" (Siegel-Causey 1991). Attachment of this muscle was described in detail by George and Berger (1966); its proximity to the external condyle made localization of the features described straightforward. Nevertheless, we found little variation among individuals, and no discrete variation among taxa.

Character 19 [tibiotarsus].--"Supratendinal bridge: (a) lateral (inferior) width greater than medial (superior); (b) widths equal" (SiegelCausey 1991). This feature is the pons supratendineus illustrated by Baumel and Witmer (1993) and was easily identifiable in our reference series. The variation described by SiegelCausey (1991) was unclear: instead of having a definable width at each extreme, the supratendinal bridge is double-concave in shape, making relative widths difficult to characterize. The paratype and almost all of the reference series are best described as having the medial width greater than the lateral, opposite to the scoring provided by Siegel-Causey (1991). The only individual that was somewhat different, a pelagicus, could best be described as having widths equal. Thus, the limited variation we observed in this character did not correspond to SiegelCausey's (1991) character states, and we found no discrete differences among taxa.

\section{Quantitative Analyses}

Determining sex.-The discriminant analysis for correcting or assigning sex cleanly assigned sex to most of the specimens (see Fig. 2). Only 15 of the 224 specimens had sexes assigned with a probability less than 0.9 of being either male or female. No change in assignment of sex was suggested for any of the 25 urile specimens.

Sexing problems occurred for 22 specimens, all pelagicus and kenyoni (Table 3 ). Ten of these specimens were not sexed by their preparators. For these 10 specimens, we used the sex they were assigned by our discriminant analysis when our analyses required that we know the

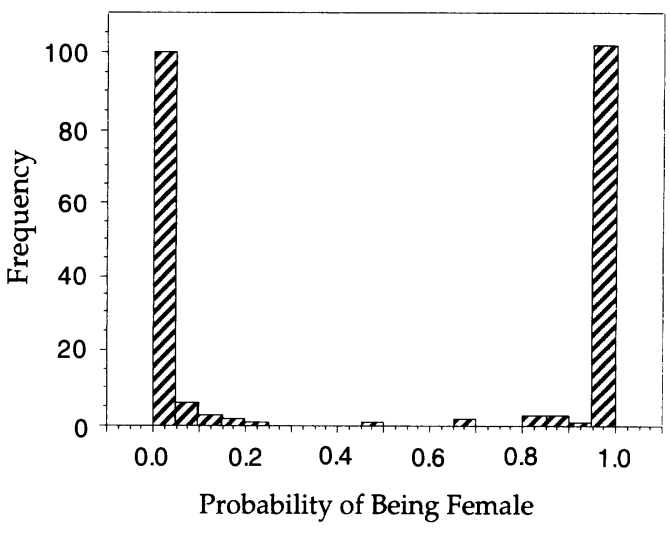

FIG. 2. Posterior probability of sex assignment, as computed from the discriminant analysis using preparator's sexing.

sex; all had posterior probabilities of 0.806 or greater of being either male or female (Table 3 ). Two of these 10 specimens were the unsexed paratypes of kenyoni (UWBM 18613, 18614), whose probabilities of being female exceeded 0.999 .

Five specimens in the Valdez sample were sexed as females by their preparators but were suggested to be males by our discriminant analysis. Three of these five specimens were young birds with bursae, and all were listed as having "smooth ovaries" (Table 3 ). We suspect these birds were young males in which the right testis was not found, either because the carcass was too rotten or because the left testis was mistaken for an ovary, causing the preparator not to look carefully enough for a right gonad. All had posterior probabilities of 0.941 or greater of being males, so we changed their sex assignment accordingly.

Our discriminant analysis challenges the sex assigned to six additional specimens from KUNHM and the Museum of Vertebrate Zoology at Berkeley (MVZ). Three had neither gonad measurements nor age data, so we changed their sex assignments to correspond to those from the discriminant analysis; posterior probabilities for these corrected sexes ranged from 0.691 (a very marginal bird) to more than 0.99 (Table 3). The other three specimens were collected by Siegel-Causey. All had gonad descriptions, so we did not change their sex assignments, despite high posterior probabilities favoring the change ( 0.872 to 0.998$)$. All of these birds were collected in the Aleutians 


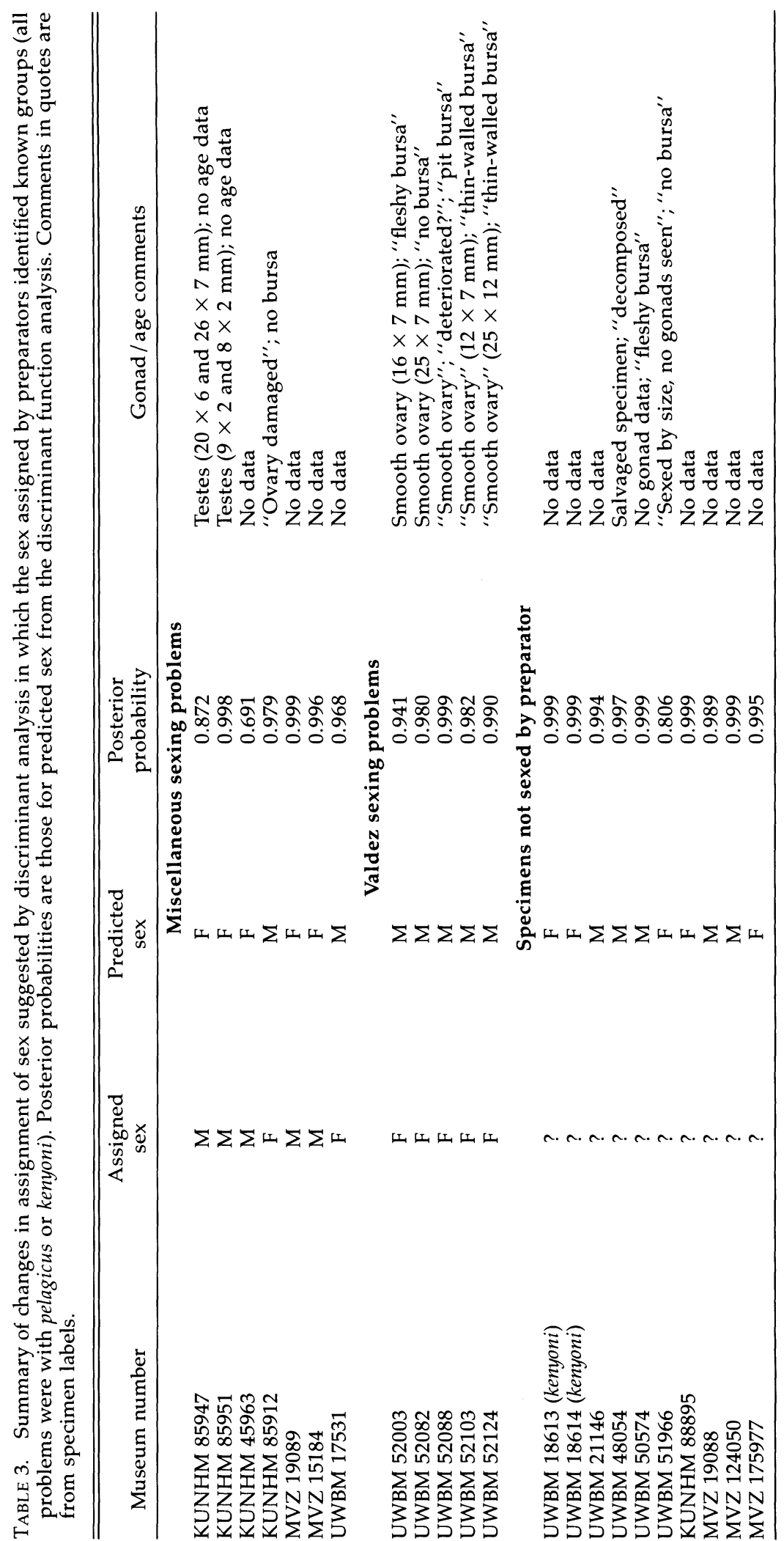




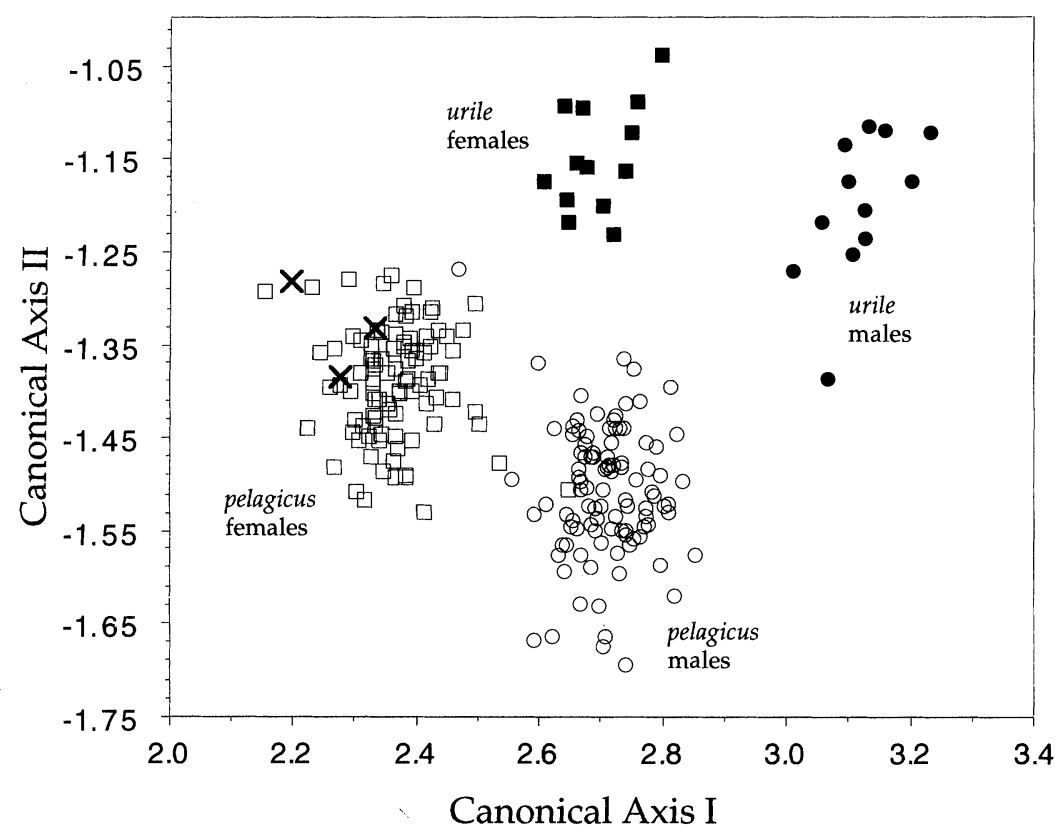

FIG. 3. Multiple discriminant analysis of urile and pelagicus separated by sex (four groups); each of the three kenyoni types that are projected onto the plot are denoted by an $\mathrm{X}$.

where pelagicus is small (see below). Small size increases the likelihood of our discriminant analysis classifying a specimen as female.

As a check on the validity of using the discriminant analysis to change assignment of sex, we summarized the morphological variation in all of our kenyoni and pelagicus specimens using PCA. When we used the assignment changes suggested by the discriminant analysis, the sexes were almost nonoverlapping in a plot of PC I versus PC II. Furthermore, only two of the birds that fell out as intermediates in this PCA (and, thus, whose sex might be questioned) were birds whose sex was assigned using the discriminant analysis. The three Siegel-Causey specimens from the Aleutians were problematic: KUNHM 85912, sexed as female, fell firmly in the male cluster, as the discriminant analysis suggested it should (though its sex was not changed); KUNHM 85947, sexed as male, fell marginally in the male cluster, corroborating Siegel-Causey's sexing; and KUNHM 85951, sexed as male, fell at the edge of the female cluster, as the discriminant analysis suggested it should (although its sex was not changed). To save space, the figure for this analysis is not presented.

Discriminating pelagicus and urile.-For this canonical analysis we used corrected sexes (20 assigned or changed; Table 3 ) and corrected species identifications (two changed). We excluded kenyoni as a known group but projected it onto the canonical axes. Excluding kenyoni as a known group was essential to the validity of this analysis because canonical analyses may have little generality when sample sizes are not considerably larger than the number of characters measured (Stevens 1996), especially when the groups being compared are as similar as the sex and species classes of these cormorants. In this four-group analysis (urile and pelagicus, males and females), the first two canonical axes explained $89 \%$ of the variance in the data. Although the measurements for male pelagicus and female urile specimens overlapped considerably, the four sex-species clusters were cleanly discriminated (Fig. 3). When projected onto these axes, the three kenyoni specimens fell with pelagicus females, suggesting that kenyoni may simply be pelagicus females (Fig. 3). As was true for the discriminant analysis used to assign sexes, two Aleutian pelagicus specimens collected by Seigel-Causey fell in the "wrong" sex class (Fig. 3).

Discriminating kenyoni and pelagicus.-Here we present a discriminant analysis attempting 
to separate the three kenyoni specimens from the 94 pelagicus females. This analysis was designed to give the validity of kenyoni the benefit of the doubt. All three kenyoni specimens appear to be females: one was sexed as such by the preparator, and all three were assigned a sex of female with posterior probabilities greater than 0.999 in our discriminant analysis of sex assignment.

Because we used 14 skeletal characters, and there are only three kenyoni specimens, kenyoni is almost certain to fall out as correctly identified in a posterior assignment of species identity. Consequently, this result will not reliably assess the validity of kenyoni. However, a good ratio of specimens to characters is available for pelagicus females. Thus, if this analysis successfully divided the pelagicus females clearly into either kenyoni or pelagicus, without intermediates, then the specific distinctness of kenyoni would be supported.

We present the results of this discriminant analysis of female kenyoni and pelagicus by plotting the posterior probabilities of these specimens being kenyoni (Fig. 4). Figure 4 divides birds into kenyoni (all from the Aleutians), pelagicus females from the Aleutians, and pelagicus females from all other localities. The pelagicus females from the Aleutians were not identified as a group to be discriminated; instead, they were plotted separately after the twogroup discriminant analysis had separated pelagicus and kenyoni (Fig. 4). Because all three kenyoni are from Amchitka Island in the Aleutians, we plotted pelagicus from the Aleutians separately to assess their similarity to kenyoni. Although the three kenyoni specimens are identified as kenyoni, only one was identified as such with an extremely high probability (0.999); the other two had posterior probabilities of 0.854 and 0.710 of being kenyoni. The looseness of this cluster raises doubt about the validity of kenyoni. More important, the combined sample of pelagicus and kenyoni females does not fall into two clearly separate clusters. This result seriously challenges the validity of kenyoni because our sample of female pelagicus was large $(n=$ 94).

This analysis could be challenged by arguing that determining the sex of kenyoni specimens using a generalized discriminant function based on sexes assigned to birds by their preparators for a mixed sample of kenyoni $(n=1)$,

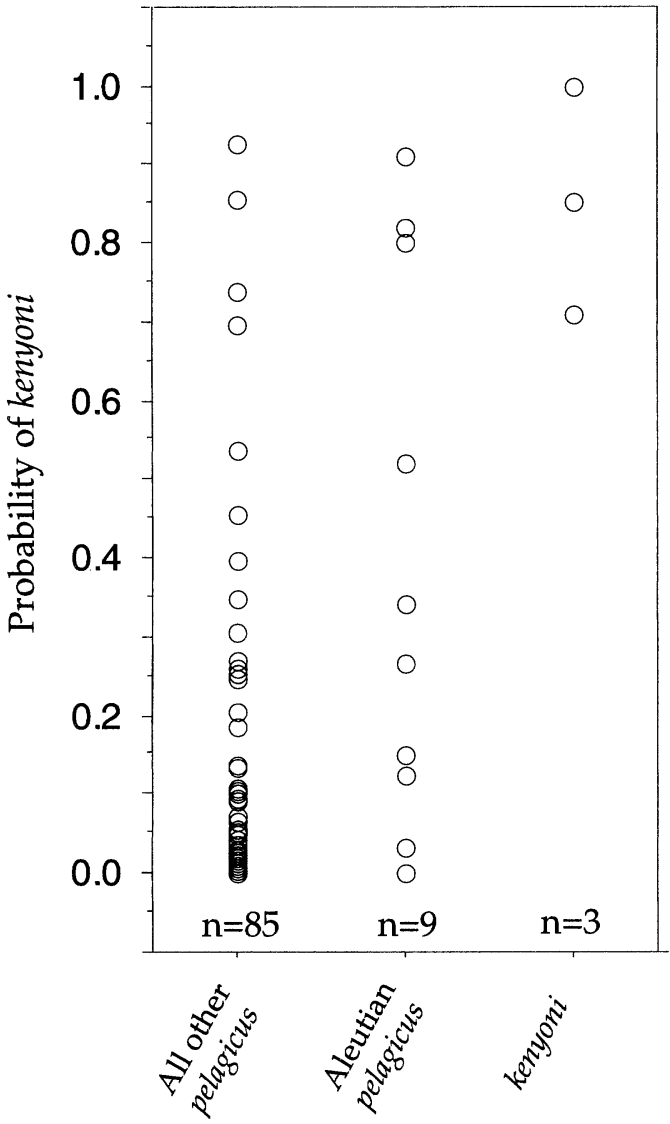

FIG. 4. Posterior probabilities of being kenyoni, as computed from the "two-group" discriminant analysis of all pelagicus females and kenyoni. Aleutian pelagicus are identified on the plot but were not an $a$ priori group in the analysis.

urile $(n=25)$ and pelagicus $(n=188)$ is invalid. For this reason, we repeated the analysis using all pelagicus $(n=196)$ and the three kenyoni specimens, but without assigning sex. The results were similar but, surprisingly, the groups were even less clearly separated because small males from Washington, California, and the Aleutians fell out between the centroids for the two groups.

Size variation in pelagicus.-An interesting result of the preceding analysis is that almost half of the pelagicus from the Aleutians fell closer to the three specimens Siegel-Causey designated as kenyoni than to other pelagicus, most of which came from Prince William Sound, Alaska (Fig. 4). This suggests that pelagicus from the Aleutians are smaller than those from sur- 
TABLE 4. Summary of principal components analysis for pelagicus and kenyoni $(n=199)$.

\begin{tabular}{lcc}
\hline \hline \multirow{2}{*}{\multicolumn{1}{c}{ Character }} & \multicolumn{2}{c}{ PC I loadings } \\
\cline { 2 - 3 } & Males & Females \\
\hline Cranium depth & 0.629 & 0.598 \\
Cranium length & 0.898 & 0.904 \\
Maxilla length & 0.813 & 0.888 \\
Coracoid length & 0.958 & 0.964 \\
Humerus length & 0.951 & 0.965 \\
Ulna length & 0.949 & 0.971 \\
Carpometacarpus length & 0.929 & 0.944 \\
Sternum length & 0.819 & 0.854 \\
Sternum width & 0.844 & 0.858 \\
Synsacrum length & 0.835 & 0.846 \\
Pelvis width & 0.800 & 0.837 \\
Femur length & 0.921 & 0.942 \\
Tibiotarsus length & 0.934 & 0.965 \\
Tarsometatarsus length & 0.919 & 0.946 \\
\hline
\end{tabular}

rounding populations. To further explore size variation in pelagicus, we summarized the variation in our morphometric measurements using separate PCAs for males and females. By separating the sexes into different analyses, we avoided confusing within-sex size variation with sex differences in the shape of the cranium. In both analyses, loadings for all characters on PC I were strong and positive (Table 4); furthermore, the 14 character coefficients were very strongly correlated between the sexes $(r=$ 0.974 ), indicating that patterns of size variation were comparable in the two sexes. Because these coefficients were so similar (Table 4), we combined the sexes in our plots of results. Thus, the standardized PC scores, computed separately for males and females, were treated as though they were the same measure of size. By combining these independent assessments of size variation, our histograms summarizing information about geographic variation in size are as general as we could make them (Fig. 5).

This analysis shows that most Aleutian specimens are small, including the three designated by Seigel-Causey (1991) as kenyoni. The distinction between the Aleutian birds and the other Alaskan specimens, including three pelagicus from the Pribilof Islands, is strong and surprising. Specimens of pelagicus from the Aleutian Islands do indeed seem to be small birds. In contrast, pelagicus from Prince William Sound and from the Pribilofs are large (Fig. 5). Apart from Prince William Sound, we have poor samples from other regions of the west coast of North America. However, most of the 14 pela-
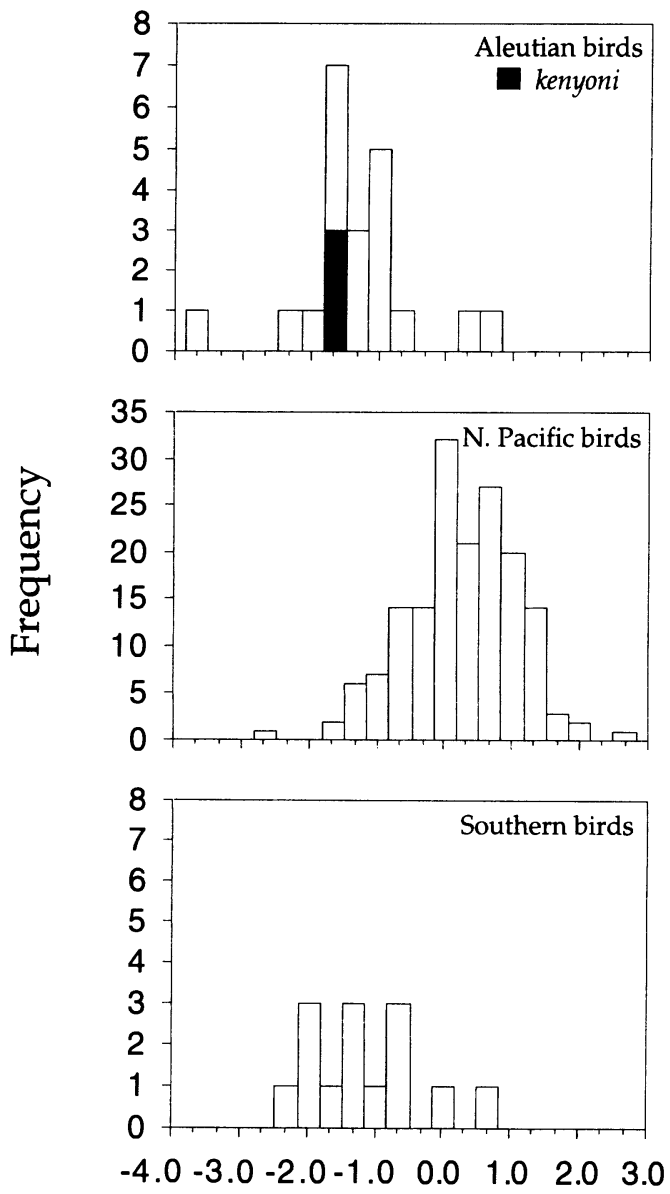

\section{Principal Component I Scores}

FIG. 5. Principal components scores summarizing size differences among Aleutian (including kenyoni), North Pacific, and southern (British Columbia, Washington, and California) pelagicus.

gicus we measured from British Columbia, Washington, and California were small and were similar in size to birds from the Aleutians (Fig. 5). Although we could have borrowed specimens from more museums, there are probably too few breeding-season specimens to determine if the size transitions in pelagicus are gradual or abrupt on the Alaska Peninsula and around the west coast of North America (Campbell et al. 1990, Johnsgard 1993).

\section{Discussion}

Qualitative evaluations.-The characters used to describe new taxa should be readily acces- 
sible to independent investigators. We encountered difficulties in identifying the exact characters on which Siegel-Causey (1991) based his description of kenyoni. Because anatomical names were used without an authoritative reference (e.g. Baumel et al. 1979) or an illustration of the features in question, most of the qualitative characters used to identify kenyoni were ambiguous.

After making the best judgments possible regarding the interpretation of Siegel-Causey's (1991) characters, we encountered further complications. The discrete taxonomic differences described by Siegel-Causey (1991: appendix 2) could not be confirmed for any of his seven diagnostic characters. Thus, no derived character, or autapomorphy, was verifiable in kenyoni. Siegel-Causey (1991) mentioned that several characters showed "modal" variation, although most were not specified and one was referred to in error (Siegel-Causey 1991:11).

Siegel-Causey (1991) stated that kenyoni is diagnosable based on "its small size and by six [really seven] autapomorphic skeletal characters." In our reanalysis, none of these seven characters was represented by a derived state in kenyoni. If kenyoni is a valid biological entity, then differences in size and shape would be the only basis for its diagnosis, a basis that SiegelCausey (1991) portrayed as unreliable.

Morphometric analyses. - Our analyses of skeletal morphometrics also failed to distinguish kenyoni. When the three "kenyoni" specimens were plotted on the two canonical axes that cleanly separate urile males, urile females, pelagicus males, and pelagicus females, all three fell into the cluster of pelagicus females. This result is consistent with our generalized sexing function that identified the kenyoni specimens as females.

Assuming that the three kenyoni specimens were females, we included them in a discriminant analysis contrasting them with all other pelagicus females. Although these specimens were successfully discriminated (an artifact of small sample size), many pelagicus females fell into the kenyoni cluster. If this analysis had yielded two discrete groups of birds, separated by a gap in morphological space, the validity of kenyoni would have been upheld. Instead, specimens from our large sample of pelagicus females $(n=94)$ were drawn into the loose cluster of kenyoni. No gap divided the specimens into two clusters, as would be expected if they were different species (Fig. 4). When we repeated this analysis using all pelagicus and kenyoni specimens, thus making no assumption about sex of the specimens, the separation was even lower. These results suggest that kenyoni is a subset of pelagicus that cannot be discriminated morphometrically.

Why do our morphometric analyses generate these messy results when Siegel-Causey's (1991) canonical analysis so cleanly separated kenyoni, pelagicus, and urile? The contrast lies in the adequacy of samples. Siegel-Causey included a total of 40 specimens in his analysis (17 urile, 20 pelagicus, and 3 kenyoni). However, he included the measurements of 37 morphometric characters in his canonical analysis. As is true of multiple regression, discriminant and canonical analyses solve a set of $p$ simultaneous equations (where $p$ is the number of variables measured) such that the ratio of between-group variance to pooled within-group variance is maximized (Overall and Klett 1972). Because the number of equations in these multivariate analyses equals the number of characters, the number of specimens included in a discriminant analysis must considerably exceed the number of characters. When this is not the case, the solution to these equations risks being unique to the particular set of specimens measured. Only when considerably more specimens than characters are measured can the results of such multivariate analyses be trusted to represent general differences between the groups being discriminated (Stevens 1996:265). Given the similarity of the three cormorants Siegel-Causey (1991) was comparing, he simply did not measure enough specimens for his canonical axes to be generally applicable to other samples representing the same groups.

Although our qualitative and morphometric analyses failed to support the validity of kenyoni, our morphometric analyses revealed that pelagicus from the Aleutians are quite small, even though they are surrounded by populations that have consistently been characterized as large (Palmer 1962, Hobson 1997). Indeed, we found that the size differences between Aleutian and nearby Alaskan populations (Fig. 5) were as great as those between Alaskan populations and populations to the south, which are treated as P. p. resplendens Audubon because of their small size (Palmer 1962). The pattern of 
variation that our results revealed for the Aleutians is consistent with the pattern of variation in at least one other Aleutian bird, the Rock Ptarmigan (Lagopus mutus gabrielsoni; Jacobsen et al. 1983). Unlike the situation for southeast Alaska and British Columbia (Warner et al. 1982, Rogers et al. 1991), the literature is still controversial concerning ice-free refugia in the western Aleutians. Ager (1983) and Hamilton and Thorson (1983) leave open the possibility of ice-free areas in the westernmost Aleutians at peak glaciation, when the Alaska Peninsula and the eastern Aleutians were fully glaciated.

Our data on the small size of Aleutian pelagicus conflict with the pattern of geographic variation summarized in Hobson (1997: appendix 2; based on Siegel-Causey's data for seven major populations of pelagicus). We cannot resolve this conflict, but we remain convinced that on the basis of skeletal characters, there is no reason to treat either the kenyoni type specimens, or the Aleutian populations of pelagicus, as a distinct species. However, both Siegel-Causey's (1991) original description and this evaluation are based only on skeletal characters. Until the behavior, ecology, and external appearance of these small Aleutian cormorants are better known, we see no evidence that kenyoni represents a valid taxon, and we suggest that it be considered a synonym of Phalacrocorax pelagicus.

\section{ACKNOWLEDGMENTS}

Brian Schmidt measured the type specimen of kenyoni. Brigitte Rohwer typed the first draft of the manuscript. Julian Baumel helped us describe our morphometric measurements. The following people from the Rohwer lab commented on the manuscript: Sharon Birks, Luke Butler, Michael Donahue, Sergei Drovetski, and Catherine Smith. Two NSF grants supported sorting, transporting, preparing, and curating the specimens salvaged from the Exxon Valdez spill, and a grant from the Exxon Valdez Trustees Council enabled us to complete the preparation of these challenging specimens. Filardi was supported as an Eddy Fellow of the Burke Museum during his work on this project. This project was based on specimens at the University of Washington Burke Museum; the Museum of Vertebrate Zoology at the University of California, Berkeley; the University of Kansas Natural History Museum; and the United States National Museum. Thanks to all of these individuals and institutions!

\section{Literature Cited}

AgER, T. A. 1983. Vegetational history of western Alaska during the Wisconsin glacial interval and the Holocene. Pages 75-93 in Late-Quaternary environments of the United States (H. E. Wright, Jr., Ed.). Volume 1. The late Pleistocene (S. C. Porter, Ed.). University of Minnesota Press, Minneapolis.

AMERICAN ORnithologists' UnION. 1998. Checklist of North American birds, 7th ed. American Ornithologists' Union, Washington, D.C.

Baumel, J. J., A. S. King, A. M. LuCAs, J. E. Breazile, AND H. E. EvANS. 1979. Handbook of avian anatomy: Nomina anatomica avium. Academic Press, London.

Baumel, J. J., And L. M. Witmer. 1993. Osteologia. Pages 45-132 in Handbook of avian anatomy: Nomina anatomica avium, 2nd ed. (J. J. Baumel, A. S. King, J. E. Breazile, H. E. Evans, and J. C. Vanden Berge, Eds.). Publications of the Nuttall Ornithological Club No. 23.

Campbell, R. W., N. K. DaWE, I. McTagGart-CoWAN, J. M. CoOper, G. W. Kaiser, And M. C. E. MCNALL. 1990. The birds of British Columbia, Vol. 1. Nonpasserines: Introduction and loons through waterfowl. Royal British Columbia Museum, Victoria.

George, J. C., And A. J. Berger. 1966. Avian myology. Academic Press, New York.

Hamilton, T. D., And R. M. Thorson. 1983. The Cordilleran ice sheet in Alaska. Pages 38-52 in Late-Quaternary environments of the United States (H. E. Wright, Jr., Ed.). Volume 1. The late Pleistocene (S. C. Porter, Ed.). University of Minnesota Press, Minneapolis.

Hobson, K. A. 1997. Pelagic Cormorant (Phalacrocorax pelagicus). In The birds of North America, no. 282. (A. Poole and F. Gill, Eds.). Academy of Natural Sciences, Philadelphia, and American Ornithologists' Union, Washington, D.C.

HowARD, H. 1929. The avifauna of Emeryville Shellmound. University of California Publications in Zoology 32:301-394.

Jacobsen, E. E., JR., C. M. White, AND W. B. EMison. 1983. Molting adaptations of Rock Ptarmigan on Amchitka Island, Alaska. Condor 85:420-426.

JOHNSGARD, P. A. 1993. Cormorants, darters and pelicans of the world. Smithsonian Institution Press, Washington, D.C.

Overall, J. H., AND C. J. KletT. 1972. Applied multivariate analysis. McGraw-Hill, New York.

OWre, O. T. 1967. Adaptations for locomotion and feeding in the Anhinga and Double-crested Cormorant. Ornithological Monographs No. 6.

PAlmer, R. S. 1962. Handbook of North American birds, Vol. 1. Loons through flamingos. Yale University Press, New Haven, Connecticut.

Rogers, R. A., L. A. Rogers, R. S. HofFMAnN, AND L. 
D. MARTIN. 1991. Native American biological diversity and the biogeographic influence of ice age refugia. Journal of Biogeography 18:623-630.

Siegel-Causey, D. 1988. Phylogeny of the Phalacrocoracidae. Condor 90:885-905.

SiEgel-CAuSEY, D. 1991. Systematics and biogeography of North Pacific shags, with a description of a new species. Occasional Papers of the University of Kansas Museum of Natural History 140:1-17.

Siegel-Causey, D., ANd C. Lefevre. 1989. Holocene records of the Antarctic Shag (Phalacrocorax [Notocarbo] bransfieldensis) in Fuegian waters. Condor 91:408-415.
Siegel-Causey, D., C. Lefevre, and A. B. SavinetSKII. 1991. Historical diversity of cormorants and shags from Amchitka Island, Alaska. Condor 93:840-852.

STEVENS, J. 1996. Applied multivariate statistics for the social sciences, 3rd ed. Lawrence Erlbaum Associates, Mahwah, New Jersey.

Warner, B. G., R. W. Mathewes, and J. J. Clague. 1982. Ice-free conditions on the Queen Charlotte Islands, British Columbia, at the height of late Wisconsin glaciation. Science 218:675-677.

Associate Editor: K. P. Dial 